\title{
Securing your relationship: Quality of intimate relationships during the COVID-19 pandemic can be predicted by attachment style
}

\author{
PLEASE REFER TO THE FINAL PUBLICATION: \\ Www.frontiersin.org/articles/10.3389/fpsyg.2021.647956/full \\ (open access)
}

Stephanie Josephine Eder ${ }^{1}$, Andrew Nicholson ${ }^{1}$, , Michał Mikołaj Stefańczyk ${ }^{2}$, Michał Pieniak $^{2}$, Judit Martínez Molina ${ }^{3}$, Ondra Pešout ${ }^{4}$, Jakub Binter ${ }^{5}$, Patrick Smela ${ }^{1}$, Frank Scharnowski ${ }^{1}$, David Steyrl ${ }^{1}$

'Department of Cognition, Emotion, and Methods in Psychology, University of Vienna, Austria, Institute of Psychology, University of Wroclaw, Poland ${ }^{3}$ Faculty of Psychology, Universitat de Barcelona, Spain ${ }^{4}$ Department of Psychology, Jan Evangelista Purkyne University, Czech Republic ${ }^{5}$ Department of Anthropology, Charles University, Czech Republic

"Corresponding Author

E-mail: Stephanie.eder@univie.ac.at 
The COVID-19 pandemic along with the restrictions that were introduced within Europe starting spring 2020 allows for the identification of predictors for relationship quality during unstable and stressful times.

The present study began as strict measures were enforced in response to the rising spread of the COVID-19 within Austria, Poland, Spain and Czech Republic. Here, we investigated quality of romantic relationships among 313 participants as movement restrictions were implemented and subsequently phased out cross-nationally. Participants completed self-report questionnaires over a period of seven weeks, where we predicted relationship quality and change in relationship quality using machine learning models that include a variety of potential predictors related to psychological, demographic and environmental variables.

On average, our machine learning tools predicted 29\% (linear models) and 22\% (non-linear models) of the variance with regard to relationship quality. Here, the most important predictors consisted of attachment style (anxious attachment being more influential than avoidance), age, and number of conflicts within the relationship. Interestingly, environmental factors such as the local severity of the pandemic did not exert a measurable influence with respect to predicting relationship quality. As opposed to overall relationship quality, the change in relationship quality during lockdown restrictions could not be predicted accurately by our machine learning models when utilizing our selected features.

In conclusion, we demonstrate cross-culturally that attachment security is a major predictor of relationship quality during COVID-19 lockdown restrictions, whereas sexual behavior, fear, pathogenic threat and the severity of governmental regulations did not significantly influence the accuracy of prediction. 


\subsection{Viral threat and political measures}

In the spring of 2020, the world-wide spread of the severe acute respiratory syndrome coronavirus 2 (SARS-CoV-2) led to stressful and insecure conditions across many nations which corresponded with severe health, economic, and social disruptions (UN, 2020; WHO, 2020). In Europe, the actual spread and effects of the virus, as well as national defensive measures taken to counteract the virus, differed between countries. For example, Spain had one of the highest infection and mortality rates in Europe, leading to limited access of medical care and the modification of public facilities to be used as field hospitals and morgues. Consequently, a nationwide state of alarm was issued, and the free movement of citizens was drastically restricted (Ministerio de la Presidencia, 2020). Despite lower case counts, Austria responded with curfew restrictions to limit the spread of the virus (BSGPK, 2020), where even countries with very low case numbers such as Czech Republic and Poland adopted strict defensive measures such as prohibiting gatherings and introducing minimal distance measures (Dziennik Ustaw, 491-522, 2020; MHCR, 2020). Varying viral impacts and medical capacities notwithstanding, all of these countries eventually introduced strict regulations, and all of them encouraged or reinforced 'social distancing' by prohibition of gatherings or movement restrictions.

\subsection{The crisis and intimate relationships}

Previous research has shown that stress impacts both relationship quality (i.e. how 'good' people subjectively perceive their relationship to be) (cf. Randall \& Bodenmann, 2009, 2017), and the way intimate partners conjointly deal with stress (Falconier et al., 2015). Relationship quality in turn is closely linked to many parameters of well-being, including psychological and bodily health (Pieh et al., 2020; South \& Krueger, 2013). Independent of the elicited stress, social isolation that removes other contacts facilitates an exclusively dyadic relationship for couples living together, and the rise in domestic violence since the implementation of movement restrictions suggest that this is not healthy for all romantic relationships (Bradbury-Jones \& Isham, 2020).

Importantly, attachment style may be an influential factor that might determine how such restrictions and stressors influence relationship quality. Attachment theory has originally been proposed as an ethological framework that explains children's reactions to stressful situations (Ainsworth \& Bowlby, 1991). Individual developmental trajectories of attachment remain highly influential in adulthood, becoming activated upon stress exposure (Gillath et al., 2006) and influencing behaviors within intimate relationships as adults (Mikulincer et al., 2002). Similar to relationship satisfaction, secure attachment is significantly correlated with greater health and well-being (McWilliams \& Bailey, 2010), where securely attached adults, whether in a relationship or not, may have overall more psychological resources to cope with distress. A variety of studies have found that securely attached individuals as opposed to those with non-secure attachment styles are affected more by distress (Zakin et al., 2003), and in turn are more prone to distort their representations of themselves and their social environment (Mikulincer et al., 1998). Furthermore, attachment security is crucial for maintaining satisfactory intimate relationships, and a number of studies have shown connections between attachment security and relationship outcomes, although determining causality poses a problem (see Mikulincer et al., 2002 for a review). Several mediators may account for such effects - for example, securely attached persons are known to engage in more mutual forms of conflict resolution than anxious or avoidant types (Corcoran \& Mallinckrodt, 2000), and conflict style in turn has a major influence on relationship satisfaction (Cann et al., 2008).

Feeney (2002) notes that as opposed to securely attached persons, insecurely attached individuals' evaluation of their own relationship is more strongly influenced by their 
partners' recent behavior. Therefore, when predicting reported relationship quality, taking recent events into account (e.g., amount of fights) in addition to attachment style to the partner, may aid in the prediction of models aiming to capture such interactions. Moreover, the same events could be appraised differently by securely and insecurely attached individuals (Collins, 1996), making it essential to consider both actual events relevant to relationships and inner working models (i.e. the attachment to the partner). Thus, depending on inner resources to deal with external stress and inner representations of social relations, the COVID-19 crisis could turn out to be stabilizing for some relationships, and destabilizing for others.

Stressful periods such as the 2003 SARS outbreak are known to have significant impacts on intimate relationships that last far longer than the actual threat, evidenced in higher stress levels and increased divorce rates (Census and Statistics Department, 2007; Lee et al., 2007). One of the social behavioral systems affected severely by stress is sexual behavior (Bodenmann et al., 2006), an important and often defining feature of intimate relationships (Hazan \& Shaver, 1987). Critically, however, the role of sexuality in stable relationships and its impact on psychological aspects such as well-being and relationships is still omitted in many studies (cf. Heiman et al., 2011). Notably, sexual behavior has indirectly been shown to be affected by external crises, where around nine months after severe threats, birth rates reliably go down throughout cultures, whereas milder threats such as low-severity storm advisories lead to increased birth rates (Evans et al., 2010; Chandra et al., 2018; Richmond \& Roehner, 2018a,b).

Recent studies have linked attachment systems to sexual behaviors (e.g. Butzer \& Campbell, 2008; Davis et al., 2006), where interestingly, sexual satisfaction might even mediate the effects of attachment anxiety on relationship satisfaction in women (Birnbaum, 2007). Moreover, securely attached persons tend to have less promiscuous and casual sex (Bogaert \& Sadava, 2002). It has furthermore been suggested that low levels of environmental pathogens coincide with more liberal sexual behavior including promiscuity and casual sex and may even account for the evolution of cross-cultural differences in sexual norms (Thornhill et al., 2009; Tybur et al., 2015). Both of these aspects make sexual behavior a particularly interesting facet of human functioning during a world-wide medical crisis, and an indispensable factor to consider when observing intimate relationships.

\subsection{Predicting relationship quality using machine-learning}

The present study investigates a period during the spring of 2020, during which strict movement restrictions in response the COVID-19 pandemic were implemented and subsequently relaxed in Austria, Poland, Spain and Czech Republic. Over a period of seven weeks, participants from these countries completed self-report questionnaires regarding their romantic relationships, partner attachment, and sexual behavior, as well as questions related to the pandemic and its perceived threat. Our goal was to determine which variables predict i) relationship quality during this crisis, and ii) any observed changes in relationship quality. We hypothesize that attachment security and sexual behavior will be important predictors of both overall relationship quality and maintaining relationship quality during these unstable times. Additionally, perceived fear of the virus, the actual pathogenic threat (local spread of infections and mortality), and the severity of the lockdown measures may further influence relationship quality. We employ two types of robust, cross-validated machine-learning models: the LASSO (least absolute shrinkage and selection operator, Tibshirani, 1996), and Extremely Randomized Trees (ET, Geurts et al., 2006). These models incorporate and control for a large number of input factors while avoiding overfitting. Extremely randomized trees are in addition non-parametric and can detect complex non-linear interactions between the variables beyond conventional correlations. 


\subsection{Participants}

\section{Methods}

Our sample consisted of 313 adult participants (mean age $=32.02$ years, SD age $=$ $12.99 ; 236$ female; 267 heterosexual) who reported to be in a romantic relationship (mean duration $=7.18$ years, $\mathrm{SD}=8.58$ years) and who repeatedly participated over a period of seven weeks. Participants resided in four main countries, which differed markedly in both prevalence of the virus and implemented measures: Austria $(n=104)$, Poland $(n=87)$, Spain $(n=65)$, Czech Republic $(n=33)$, and four additional regions (Germany, Netherlands, Italy, Pakistan; $n=24)$. No exclusion criteria were applied, but all cases with missing variables of interest were excluded for the machine learning models (see Results for trails included in each model).

\subsection{Procedure}

Weekly surveys (administered via SoSci Survey, www.soscisurvey.com) were sent via e-mail to participants who had been recruited over social media. Participants were informed about the aim of study and that they could stop participating at any point; they were fully debriefed and received the option to leave a contact address in order to be informed of the results of the study. All communication with the participants took place in their native language.

\subsection{Timeframe and sociopolitical climate}

The study period coincided with the implementation and loosening of governmental measures including curfews in the participating countries. The first survey was completed by participants between March $16^{\text {th }}$ and $22^{\text {nd }}$ (coinciding with the first curfews in Austria, a nationwide state of alarm in Spain and Czech Republic and a state of epidemic danger in Poland). The last survey was completed between April $27^{\text {th }}$ and May $3^{\text {rd }}, 2020$, when the most drastic restrictions had been lifted in all countries.

\subsection{Surveys}

To measure attachment security, we administered the Experiences in Close Relationships Revised scale (ECR-R, Fraley et al, 2000) at the beginning and at the end of the study, which allowed us to estimate the temporal stability of this input feature. If available, validated translations of the questionnaire were used, otherwise the questionnaire was translated by a native speaker and reviewed by another native speaker (Polish version: Lubiewska et al, 2016; Czech version: Cígler et al, 2019; Spanish version modified from: Fernández-Fuertes et al, 2011).

Additionally, we assessed information regarding participants' romantic relationship. Here, we surveyed one general question directly targeting perceived relationship quality and one question each for 'tolerance for each other', 'joint activities with the partner', 'discussing important topics with the partner' and 'taking time for each other' are asked on a 5-point Likert scale. Additionally, one question on the amount of conflicts and several questions on sexual behavior and touching interactions are asked.

Moreover, we asked about perceived threat of the virus, perceived health and sportive activity. Demographic and personal items were collected, such as sex, sexual orientation, relationship status, and country of residence. Categorical features were one-hot encoded. We also used a 'stringency index' for each country and week as described by Petherick et al. (2020), denoting the gravity of governmental restrictions in response to the pandemic, as well utilized confirmed cases and deaths per million citizens (Sources: Eurostat 2020; Hale et al., 2020) for each week and country as a measure of viral spread and mortality.

In summary, Table 1 lists all input features included in our machine learning models. 


\subsection{Analysis}

We fit two types of machine learning models, each trying to predict reported relationship quality and change in relationship quality, respectively. One linear (LASSO [least absolute shrinkage and selection operator], Tibshirani, 1996), one non-linear (ET [Extremely Randomized Trees], Geurts et al., 2006). The models were evaluated with nested crossvalidation (90/10, 100 repeats each), where hyper-parameter tuning took place in the inner loop and only used training data from the current loop (Cawley \& Talbot, 2010). Crossvalidation was stratified, controlling for participant ID to counteract subject cluster learning. We compared the models' performance in the respective hold-out sets to a trivial predictor, which uses the mean of all target variables for each prediction.

Notably, the variance of the testing set explained by predictions trained on the training set will be smaller than when a conventional model is being fit to all of the data, however, the results are models capable of actual predictions for unknown data. Furthermore, our models are particularly suited to handle many input features while all the same avoiding overfitting. Extremely randomized trees in particular are non-parametric (the LASSO, in contradiction, imposes a linear structure) and handle complex interactions between the variables, beyond what regression analysis could encompass. To estimate the predictive value of the input features, we report the median permutation feature importance for the better-performing model as the proportional loss of explained variance if the input is replaced by a random (noninformative) array of that variable (Breiman, 2001). Further, we also show model-based feature importance (the coefficients assigned to input features by the models normalized each by the sum of all coefficients). Analyses were conducted in Python 3.7.7. (Scikit-learn 0.22.2., Pedregosa et al., 2011) and R (R Core Team, 2017). 


\subsection{Relationship quality throughout the crisis}

Overall, relationship quality remained fairly constant throughout the curfews, as the majority of all participants did not report any changes. However, exactly one third of all participants did report changes in their relationship quality. We aim at predicting these interindividual differences regarding the stability of relationship quality below.

\subsection{Predicting overall relationship quality}

On average, around 30 percent of the variance in ratings on relationship quality during the lockdown was predicted by the linear models (LASSO), whereas the non-linear models (ET) on average predicted 22 percent of this variance. (LASSO: $\mathrm{R}_{\text {avg }}^{2}=0.29, \mathrm{R}_{\text {median }}^{2}=0.33$, $p<0.001$; ET: $\left.\mathrm{R}_{\text {avg }}^{2}=0.22, \mathrm{R}_{\text {median }}^{2}=0.23, p<0.001 ; \mathrm{N}_{\text {trials }}=731\right)$.

Based on permutation feature importance (PFI), the most important input features with an importance over 5\% for the linear model were age (13.92\%, younger age predicting higher quality), conflicts (12.88\%, less fights predicting higher quality) and attachment anxiety (8.62\%, less anxiety/avoidance scores predicting higher quality) (Fig. 1A); whereas for the non-linear model, conflicts $(6.32 \% \%)$, joint activities $(5.68 \%)$, time investment $(7.24 \%)$ and attachment anxiety $(5.60 \%)$ were contributing most.

The most important features remain the same when assessing model-based feature importance, although in a different order: Conflicts (0.13), attachment anxiety (0.12), age (0.11), joint activity (0.09), time investment (0.07) and avoidant attachment (0.07) for the linear models (Fig. 1B); joint activity (0.25), conflicts (0.14), attachment anxiety (0.13), avoidant attachment (0.09), time investment (0.09) and tolerance (0.06) for the non-linear models. For the slightly better performing linear models, Figure 1 shows the permutation feature importance and model-based importance of all features.

The above models consider attachment security and avoidant attachment as two separate input features. To assess the importance of attachment relative to other variables, we then combined both subscales of the ECR-R and used it a single feature. Here, the ECR-R score indicating overall attachment security is by far the most important feature (responsible for $19.11 \%$ and $11.03 \%$ of the explained variance in the linear and non-linear model, respectively).

Figure 1C shows how this most informative predictor (the sum of anxiety and avoidance) is linked to relationship quality in our non-linear models. It indicates that a nonlinear use of this measure is most beneficial when predicting relationship quality.

\subsection{Changes in relationship quality cannot be predicted}

As opposed to the overall quality, changes in relationship quality could not be predicted by our models better than by a trivial predictor (LASSO: $\mathrm{R}_{\text {avg }}^{2}=-0.14, \mathrm{R}_{\text {median }}^{2}=-$ $0.06, p=1$; ET: $\mathrm{R}_{\text {avg }}^{2}=-0.31, \mathrm{R}_{\text {median }}^{2}=-0.14, p=1 ; \mathrm{N}_{\text {trials }}=708$ ). The only feature with a modelbased feature importance above zero in both model types was the participants' answer to the item 'my partner takes time for me' (model-based feature importance: $\mathrm{LASSO}=0.58$; ET= 0.24 ; $\left.\mathrm{PFI}_{\text {both }}=0\right)$. A post-hoc analysis revealed a Pearson correlation of $\mathrm{R}=0.21\left(\mathrm{BF}_{01}=\right.$ 0.695 ) between this time-investment and the change in relationship satisfaction over time. 

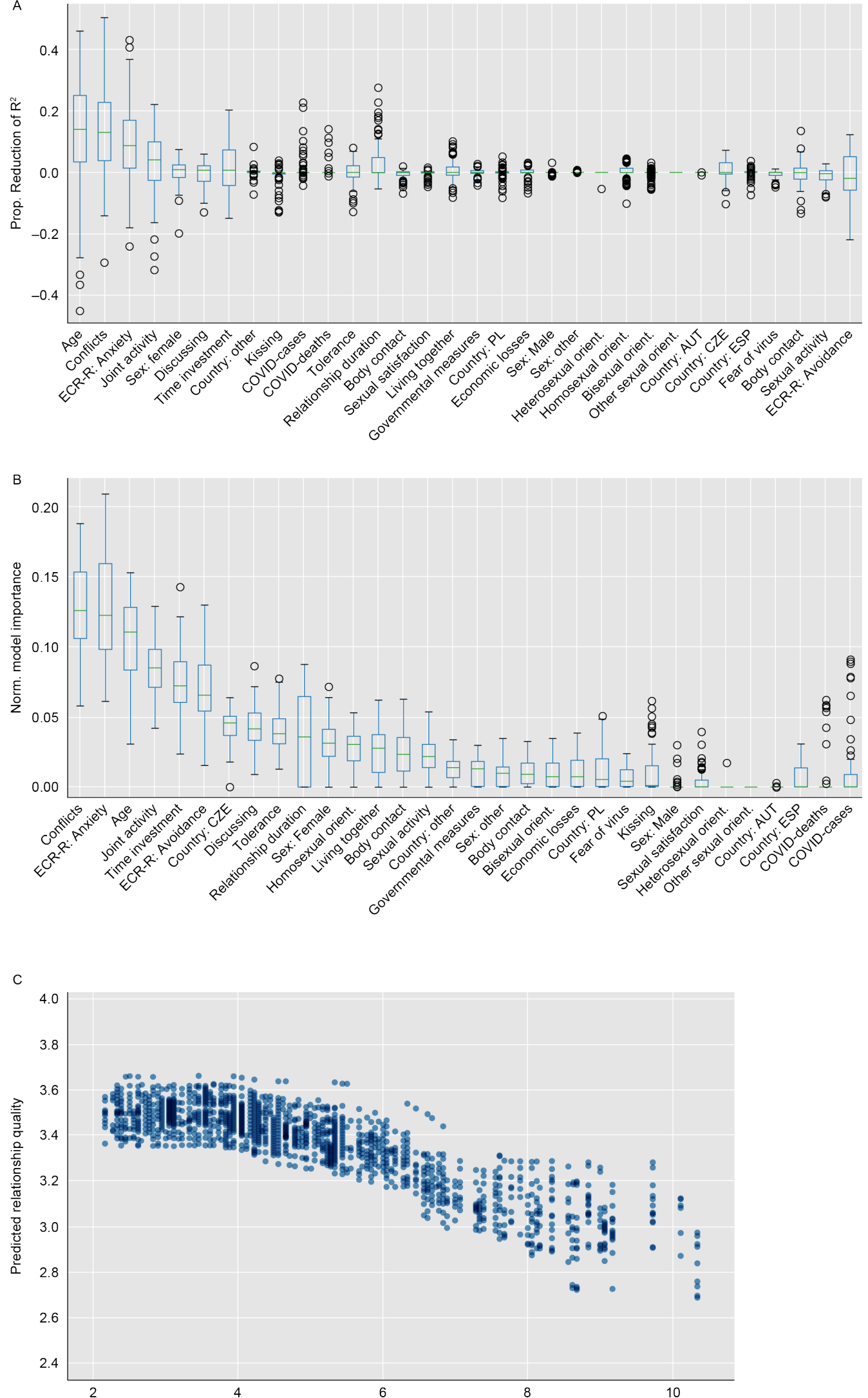

Figure 1. Permutation feature importance (A) and model-based feature importance (B) over linear models with relationship quality as a target.

C) Use of attachment security (overall score) as a predictor by the non-linear models. 
An important predictor for relationship quality was attachment security as measured by the ECR-R, and we performed a post-hoc group comparison with all participants that had filled in the questionnaire both times (around four weeks apart). There was no difference in attachment security between the beginning and end phase of the lockdown (mean decrease by $0.05 \%, \mathrm{BF}_{01}=14.924$; shared variance $=76.91 \% ; N=140$ ). This is in line with the good 3-week test-retest reliability reported for the ECR-R (84-85\% shared variance, Sibley et al., 2005). 
The aim of the current present study was to predict relationship quality as movement restrictions in response to the COVID-19 pandemic are implemented and loosened in four European states. Using attachment as one of the most important predictors, our linear models predicted around $30 \%$ of the variance in self-reported relationship quality. This is in line with studies finding that ECR-R scores explain a large amount of between-person variation of emotional experiences with the partner (Sibley et al., 2005).

\subsection{Predictors of relationship quality}

Nationwide movement restrictions constitute special circumstances for people in romantic relationships; due to curfews, couples become each other's only social contact. Indeed, in such unstable times, people may have to endure increased stress levels in response to the medical threat and subsequent societal changes, which might further influence relationship dynamics. In line with our hypotheses, attachment security was a major predictor of relationship satisfaction during the time of curfews and social restrictions. This corroborates previous studies that have linked attachment styles to relationship quality (e.g. Mikulincer et al., 2002) and this effect may even be increased by the stressful effects of the crisis by activating those patterns (cf. Gillath et al., 2006). Mikulincer and colleagues (2002) propose three main avenues by which relationship quality may be influenced by attachment style: secure attachment may orient individuals towards a positive bias of dyadic interactions, positive representations of the self and others which affect conflict management, as well as the satisfaction of other psychological needs (Mikulincer et al., 2002). Interestingly, in the current study, the dimension 'anxiety' was a more important predictor that the subscale 'avoidance'. Potentially, this difference in enhanced by a general decrease of external security in times of crises. Secure attachment may further relate to an internal locus of control (Hexel, 2003), and securely attached individuals may have more mechanisms to cope with the stress a world-wide crisis elicits (Feeney, 1995). Indeed, an analysis of subjective health in our sample over time shows that attachment security is a predictor of a heightened sense of health (Eder et al., 2020, August 22). This means that the effects of secure attachment are not refined to the relationship per se, but may exert an influence over various psychological mechanisms.

Importantly, the accuracy of predictions for relationship quality could have been enhanced by taking both partners into account. Senchak and Leonard (1992) report that the pairing of attachment styles rather than individual attachment is associated with marital satisfaction. Specifically, as opposed to couples where both partners are securely attached ('secure couples'), couples where a securely attached person is in a relationship with an insecurely attached person do not differ from 'insecure couples'. However, securely attached persons tend to pair with securely attached partners (Senchak \& Leonard, 1992), potentially buffering this confounding factor.

Attachment has traditionally been classified into attachment styles (Ainsworth \& Bowlby, 1991; Feeney \& Noller; 1990), although many have argued that attachment security should be treated as a continuum (Fraley et al., 2015; Lubiewska \& Van de Vijver, 2020; Haslam et al., 2020). Indeed, the way our non-linear models use the ECR-R score to optimize the predictions of relationship quality (Fig. 1C) suggests that a non-continuous use of the variable (divided to the categories secure/less secure) may be justified as a simplified measure when investigating implications for adult relationship satisfaction.

Unexpectedly, the age of participants had a very high feature importance, where younger participants self-reported higher quality scores with respect to their relationships. Some longitudinal evidence may support this conclusion, such as an increase in unpleasant aspects in the relationship over time (Birditt et al., 2009); and weak correlations between younger age and higher relationship satisfaction have been reported previously (Lenger et al., 
2008). However, both longitudinal and cross-sectional studies would be of high value to follow up on this little investigated aspect of relationships.

In both linear and non-linear models, another important predictor of how participants rated their relationship quality was the number of arguments with the partner they reported per week, where frequency of conflicts has previously been shown to cause lowered relationship quality (Kluwer \& Johnson, 2007). Our results confirm the predictive value of amount of conflicts, and suggest that simplified behavioral observations or surveys on relationship quality need to include this aspect. Thus, our findings emphasize the dimension 'agreement' over other dimensions of intimate relationships, such as intimacy and independence, but also sexuality (cf. Hassebrauk \& Fehr, 2002). This is surprising, since engaging in sexual behavior is an important aspect of pair-bonding that has repeatedly been demonstrated (Birnbaum \& Finkel, 2015; McNulty, Wenner, \& Fisher, 2016). Moreover, despite the fact that sexual satisfaction cannot predict changes in relationship quality or vice versa in some studies (Byers, 2005; Joel et al., 2020), as is in line with our results, it does seem to relate to relationship quality at a given point in time (Byers, 2005; Joel et al., 2020), and in some studies even to future relationship quality (Fallis et al., 2016). However, the actual number of sexual intercourse alone is no telling measure of relationship satisfaction (Loewenstein et al., 2015), and a curvilinear relationship between sexual frequency and overall happiness has been proposed (Muise, Schimmak, \& Impett, 2015), which, if applicable to relationship satisfaction, should nevertheless have been detected by our nonlinear models. 'Sexual afterglow' - evidenced in elevated levels of sexual satisfaction - might facilitate pair bonding beyond sex (Meltzer et al., 2017); however, the effect could have been captured by our input feature 'sexual satisfaction'. Overall, no aspect of sexual behavior or satisfaction was predictive for reported relationship quality in our models, and our data do not provide further evidence to the large body of literature connecting the variables. A deeper understanding of circumstances and motives ('sexual goals') of sexual behavior in romantic relationships may help to clarify this relationship (cf. Muise, Boudreau, \& Rosen, 2017).

Previous studies have found that changes in relationship quality are harder to predict than relationship quality at a given point in time (Joel et al., 2020). Our results show that this is the case even in a period where many quantifiable environmental factors act on intimate relationships, since our models completely fail to predict changes in relationship quality. The fact that we did not observe changes for most participants may in part account for this difficulty. None of the environmental features or the features that do predict general relationship quality in the sample seem to add information about changes in quality. An exception to that is the perceived time investment by the partner, which had a non-zero model-based feature importance and was post-hoc shown to correlate with changes in relationship quality. While this study can not conclusively support the role of time investment for temporal changes in relationship quality, this may provide an interesting starting point for further studies.

\subsection{Generalizability}

The cross-cultural composition of our sample and the fact that our models are evaluated by their performance on unknown subjects promises a relatively high generalizability for western cultures, however, our results may not hold true for older populations. Furthermore, we did not exclude or control for clinical psychological conditions, which might have distorted the results obtained in these globally stressful times. Crosscultural studies on similar situations are needed to further investigate the role of attachment style in crisis-like situations, and studies taking into account both partners in a romantic relationship could further benefit such predictions (dyadic data, see Kenny et al., 2006). 


\subsection{Conclusion}

The current study provides evidence on the complex interactions between relationship quality, attachment style, and demographic variables in couples during exceptional and stressful circumstances. We examined and predicted relationship quality as lockdown measures due to the COVID-19 pandemic are implemented in four European states. We found that attachment security was a highly important predictor for relationship quality, and that country of residence, case counts, and the stringency of governmental measures did not contribute to accurate predictions. Changes in relationship quality could not be accurately predicted using the currently implemented machine learning approach.

In conclusion, we demonstrate that attachment security is an important predictor of relationship quality during the unstable times of the COVID-19 pandemic, in comparison to 371 fear, sexuality and environmental factors such as the stringency of movement restrictions. 
374 Table 1. Input features used to predict reported relationship quality and change in relationship 375 quality.

Target

Relationship quality and change in quality

Features $\quad$ Country, viral spread and mortality, stringency of restrictioß§8 8

$$
\text { Age+ }
$$

Sex

Sex. orientation

ECR-R anxiety+

ECR-R avoidance

Mean fear

Having children

Health

Sexual activity

Sexual satisfaction

Physical contact

Kissing

Discussing

Living with partner

Tolerance

Joint activity+

Time investment +

Conflicts+

$394 \quad$ Note.

Relationship duration quality are marked with ' + '. None of the features had a median PFI greater than zero for the

Figure 1. Permutation feature importance (A) and model-based feature importance (B) over

C) Use of attachment security (overall score) as a predictor by the non-linear models. 


\section{References}

Ainsworth, M., \& Bowlby, J. (1991). An ethological approach to personality development. American Psychologist, 46(4), 331-341. https://doi.org/10.1037/0003-066X.46.4.333

Alley, J., Owen, R. Y., Wawrzynski, S. E., Lasrich, L., Ahmmad, Z., Utz, R., \& Adkins, D. E. (2020). Illness, Social Disadvantage, and Sexual Risk Behavior in Adolescence and the Transition to Adulthood. Arch Sex Behav. https://doi.org/10.1007/s10508-02001747-2

Birditt, K. S., Jackey, L. M., \& Antonucci, T. C. (2009). Longitudinal patterns of negative relationship quality across adulthood. Journals of Gerontology Series B: Psychological Sciences and Social Sciences, 64(1), 55-64. https://doi.org/10.1093/geronb/gbn031

Birnbaum, G. E. (2007). Attachment orientations, sexual functioning, and relationship satisfaction in a community sample of women. Journal of Social and Personal Relationships, 24(1), 21-35. https://doi.org/10.1177/0265407507072576

Birnbaum, G. E., \& Finkel, E. J. (2015). The magnetism that holds us together: Sexuality and relationship maintenance across relationship development. Current Opinion in Psychology, 1, 29-33. https://doi.org/10.1016/j.copsyc.2014.11.009

Bodenmann, G., Ledermann, T., Blattner, D., \& Galluzzo, C. (2006). Associations among everyday stress, critical life events, and sexual problems. The Journal of nervous and mental disease, 194(7), 494-501. https://doi.org/10.1097/01.nmd.0000228504.15569.b6

Bogaert, A. F., \& Sadava, S. (2002). Adult attachment and sexual behavior. Personal Relationships, 9(2), 191-204. https://doi.org/10.1111/1475-6811.00012

Bradbury - Jones, C., \& Isham, L. (2020). The pandemic paradox: the consequences of COVID - 19 on domestic violence. Journal of clinical nursing, 29(13-14), 2039-2730. https://doi.org/10.1111/jocn.15296

Breiman, L. (2001). Random Forests. Machine Learning 45, 5-32. https://doi.org/10.1023/A:1010933404324

Bundesministerium für Soziales, Gesundheit, Pflege und Konsumentenschutz [BSGPK] $\left(2020\right.$, May $\left.3^{\text {rd }}\right)$. Coronavirus - Rechtliches [Coronavirus - Legal aspects]. https://www.sozialministerium.at/Informationen-zum-Coronavirus/Coronavirus--Rechtliches.html

Butzer, B., \& Campbell, L. (2008). Adult attachment, sexual satisfaction, and relationship satisfaction: A study of married couples. Personal relationships, 15(1), 141-154. https://doi.org/10.1111/j.1475-6811.2007.00189.x

Bogaert, A. F., \& Sadava, S. (2002). Adult attachment and sexual behavior. Personal Relationships, 9(2), 191-204. https://doi.org/10.1111/1475-6811.00012

Byers, E. S. (2005). Relationship satisfaction and sexual satisfaction: A longitudinal study of individuals in long-term relationships. Journal of sex research, 42(2), 113-118. https://doi.org/10.1080/00224490509552264

Cann, A., Norman, M. A., Welbourne, J. L., \& Calhoun, L. G. (2008). Attachment styles, conflict styles and humour styles: Interrelationships and associations with relationship satisfaction. European Journal of Personality: Published for the European Association of Personality Psychology, 22(2), 131-146. https://doi.org/10.1002/per.666

Cawley, G. C., \& Talbot, N. L. (2010). On over-fitting in model selection and subsequent selection bias in performance evaluation. The Journal of Machine Learning Research, 11, 2079-2107. https://www.jmlr.org/papers/volume11/cawley10a/cawley10a.pdf 
Census and Statistics Department. (2007, November). Marriage and divorce trends in Hong Kong, 1981 to 2006. Hong Kong Monthly Digest of Statistics. Retrieved from https://www.statistics.gov.hk/pub/B70711FB2007XXXXB0100.pdf

Chandra, S., Christensen, J., Mamelund, S. E., \& Paneth, N. (2018). Short-term birth sequelae of the 1918-1920 influenza pandemic in the United States: state-level analysis. American journal of epidemiology, 187(12), 2585-2595. https://doi.org/10.1093/aje/kwy153

Cígler, H., Cvrčková, A., Daňsovác, P., Hašto, J., Charvát, M., Ježek, S., ... Seitl, M. (2019). Experiences in close relationships: České verze metod pro měření vazby vycházející z dotazníku ECR. E-psychologie, 13(4) 57-74. https://doi.org./10.29364/epsy.359

Collins, N. L. (1996). Working models of attachment: Implications for explanation, emotion, and behavior. Journal of personality and social psychology, 71(4), 810. https://doi.org/10.1037/0022-3514.71.4.810

Corcoran, K. O. C., \& Mallinckrodt, B. (2000). Adult attachment, self-efficacy, perspective taking, and conflict resolution. Journal of Counseling \& Development, 78(4), 473-483. https://doi.org/10.1002/j.1556-6676.2000.tb01931.x

Davis, D., Shaver, P. R., \& Vernon, M. L. (2004). Attachment style and subjective motivations for sex. Personality and Social Psychology Bulletin, 30(8), 1076-1090. https://doi.org/10.1177/0146167204264794

Davis, D., Shaver, P. R., Widaman, K. F., Vernon, M. L., Follette, W. C., \& Beitz, K. (2006). "I can't get no satisfaction": Insecure attachment, inhibited sexual communication, and sexual dissatisfaction. Personal Relationships, 13(4), 465483. https://doi.org/10.1111/j.1475-6811.2006.00130.x

Duncan, L. A., Schaller, M., \& Park, J. H. (2009). Perceived vulnerability to disease: Development and validation of a 15-item self-report instrument. Personality and Individual differences, 47(6), 541-546. https://doi.org/10.1016/j.paid.2009.05.001

Dziennik Ustaw (2020), poz. 433-697 [Journal of Laws of the Republic of Poland]. http://isap.sejm.gov.pl/isap.nsf

Eder, S.J., Steyrl, D., Stefanczyk, M.M, Pieniak, M., Martínez, J., Pešout, O., Binter, J., Smela, P., Scharnowski, F., \& Nicholson, A. (2020, August 22). Predicting fear and health during the COVID-19 pandemic using machine learning: A cross-national longitudinal study. Preprint. https://doi.org/10.31234/osf.io/wdmvh

Eurostat (2020, April 23 $3^{\text {rd }}$ ). Population on 1 January (online data code:TPS00001). Retrieved from https://ec.europa.eu/eurostat/databrowser/view/tps00001/default/table?lang=en

Evans, R. W., Hu, Y., \& Zhao, Z. (2010). The fertility effect of catastrophe: US hurricane births. Journal of Population Economics, 23(1), 1-36. https://doi.org/10.1007/s00148008-0219-2

Falconier, M. K., Jackson, J. B., Hilpert, P., \& Bodenmann, G. (2015). Dyadic coping and relationship satisfaction: A meta-analysis. Clinical Psychology Review, 42, 28-46. https://doi.org/10.1016/j.cpr.2015.07.002

Fallis, E. E., Rehman, U. S., Woody, E. Z., \& Purdon, C. (2016). The longitudinal association of relationship satisfaction and sexual satisfaction in long-term relationships. Journal of Family Psychology, 30(7), 822-831. https://doi.org/10.1037/fam0000205

Feeney, J. A. (1995). Adult attachment, coping style and health locus of control as predictors of health behaviour. Australian Journal of Psychology, 47(3), 171-177. https://doi.org/10.1080/00049539508257520

Feeney, J. A. (2002). Attachment, marital interaction, and relationship satisfaction: A diary study. Personal Relationships, 9(1), 39-55. https://doi.org/10.1111/1475-6811.00003

Feeney, J. A., \& Noller, P. (1990). Attachment style as a predictor of adult romantic relationships. Journal of personality and Social Psychology, 58(2), 281-291. https://doi.org/10.1037/0022-3514.58.2.281 
Fernández-Fuertes, A. A., Orgaz, B., Fuertes, A., \& Carcedo, R. (2011). La evaluación del apego romántico en adolescentes españoles: validación de la versión reducida del Experiences in Close Relationships-Revised (ECR-R). Anales de psicología, 27(3), 827-833. Retrieved from https://revistas.um.es/analesps/article/download/135561/123641/

Fleischman, D. S., Hamilton, L. D., Fessler, D. M., \& Meston, C. M. (2015). Disgust versus lust: Exploring the interactions of disgust and fear with sexual arousal in women. PLoS One, 10(6). https://doi.org/10.1371/journal.pone.0118151

Fraley, R. C., Hudson, N. W., Heffernan, M. E., \& Segal, N. (2015). Are adult attachment styles categorical or dimensional? A taxometric analysis of general and relationshipspecific attachment orientations. Journal of Personality and Social Psychology, 109(2), 354-368. https://doi.org/10.1037/pspp0000027

Fraley, R. C., Waller, N. G., \& Brennan, K. A. (2000). An item response theory analysis of self-report measures of adult attachment. Journal of personality and social psychology, 78(2), 350. https://doi.org/10.1037/0022-3514.78.2.350

Geurts, P., Ernst, D., \& Wehenkel, L. (2006). Extremely randomized trees. Machine learning, 63(1), 3-42. https://doi.org/10.1007/s10994-006-6226-1

Gillath, O., Mikulincer, M., Fitzsimons, G. M., Shaver, P. R., Schachner, D. A., \& Bargh, J. A. (2006). Automatic activation of attachment-related goals. Personality and Social Psychology Bulletin, 32(10), 1375-1388. https://doi.org/10.1177/0146167206290339

Hale, T., Webster, Anna Petherick, Toby Phillips, and Beatriz Kira (2020, May $18^{\text {th }}$ ). Oxford COVID-19 Government Response Tracker, Blavatnik School of Government. https://www.bsg.ox.ac.uk/research/research-projects/coronavirus-governmentresponse-tracker

Haslam, N., McGrath, M. J., Viechtbauer, W., \& Kuppens, P. (2020). Dimensions over categories: a meta-analysis of taxometric research. Psychological Medicine, 1-15. https://doi.org/10.1017/S003329172000183X

Hassebrauck, M., \& Fehr, B. (2002). Dimensions of relationship quality. Personal relationships, 9(3), 253-270. https://doi.org/10.1111/1475-6811.00017

Hazan, C., \& Shaver, P. (1987). Romantic love conceptualized as an attachment process. Journal of personality and social psychology, 52(3), 511. https://doi.org/10.1037/0022-3514.52.3.511

Heiman, J. R., Long, J. S., Smith, S. N., Fisher, W. A., Sand, M. S., \& Rosen, R. C. (2011). Sexual satisfaction and relationship happiness in midlife and older couples in five countries. Archives of sexual behavior, 40(4), 741-753. https://doi.org/10.1007/s10508-010-9703-3

Hexel, M. (2003). Alexithymia and attachment style in relation to locus of control. Personality and Individual Differences, 35(6), 1261-1270. https://doi.org/10.1016/S0191-8869(02)00333-1

Joel, S., Eastwick, P. W., Allison, C. J., Arriaga, X. B., Baker, Z. G., Bar-Kalifa, E., ... \& Carmichael, C. L. (2020). Machine learning uncovers the most robust self-report predictors of relationship quality across 43 longitudinal couples studies. Proceedings of the National Academy of Sciences, 117(32), 19061-19071. https://doi.org/10.1073/pnas.1917036117

Kenny, D.A., Kashy, D.A., \& Cook, W.L. (2006). Dyadic Data Analysis. Guilford Press. Kluwer, E. S., \& Johnson, M. D. (2007). Conflict frequency and relationship quality across the transition to parenthood. Journal of Marriage and Family, 69(5), 1089-1106. https://doi.org/10.1111/j.1741-3737.2007.00434.x

Lee, A. M., Wong, J. G., McAlonan, G. M., Cheung, V., Cheung, C., Sham, P. C., ... Chua, S. E. (2007). Stress and psychological distress among SARS survivors 1 year after the 

https://doi.org/10.1177/070674370705200405

Lenger, K. A., Gordon, C. L., \& Nguyen, S. P. (2019). A word to the wise: Age matters when considering mindfulness in romantic relationships. Contemporary Family Therapy, 41(2), 115-124. https://doi.org/10.1007/s10591-018-9479-5

Loewenstein, G., Krishnamurti, T., Kopsic, J., \& Mcdonald, D. (2015). Does increased sexual frequency enhance happiness?. Journal of Economic Behavior \& Organization, 116, 206-218. https://doi.org/10.1016/j.jebo.2015.04.021

Lubiewska, K., Gogowska, K., Mickiewicz, K., Wyrzykowska, E., Winiewski, C., Izdebski, P., \& Staffa, U. (2016). Skala Experience in Close Relationships-Revised: Struktura, Rzetelno oraz Skrócona Wersja Skali w Polskiej Próbie. Psychologia Rozwojowa, 21 (1), 49-63. https:doi.org/10.4467/20843879PR.16.004.4793

Lubiewska, K., \& Van de Vijver, F. J. (2020). Attachment categories or dimensions: The Adult Attachment Scale across three generations in Poland. Journal of Social and Personal Relationships, 37(1), 233-259. https://doi.org/10.1177/0265407519860594

McNulty, J. K., Wenner, C. A., \& Fisher, T. D. (2016). Longitudinal associations among relationship satisfaction, sexual satisfaction, and frequency of sex in early marriage. Archives of Sexual Behavior, 45(1), 85-97. https://doi.org/10.1007/s10508014-0444-6

McWilliams, L. A., \& Bailey, S. J. (2010). Associations between adult attachment ratings and health conditions: Evidence from the National Comorbidity Survey Replication. Health Psychology, 29(4), 446-453. https://doi.org/10.1037/a0020061

Meltzer, A. L., Makhanova, A., Hicks, L. L., French, J. E., McNulty, J. K., \& Bradbury, T. N. (2017). Quantifying the sexual afterglow: The lingering benefits of sex and their implications for pair-bonded relationships. Psychological Science, 28(5), 587-598. https://doi.org/10.1177/0956797617691361

Mikulincer, M., Florian, V., Cowan, P. A., \& Cowan, C. P. (2002). Attachment security in couple relationships: A systemic model and its implications for family dynamics. Family process, 41(3), 405-434. https://doi.org/10.1111/j.15455300.2002.41309.x

Mikulincer, M., Orbach, I., \& Iavnieli, D. (1998). Adult attachment style and affect regulation: Strategic variations in subjective self-other similarity. Journal of Personality and Social Psychology, 75(2), 436. https://doi.org/10.1037/00223514.75.2.436

Ministerio de la Presidencia (2020). Real Decreto 463/2020, de 14 de marzo, por el que se declara el estado de alarma para la gestión de la situación de crisis sanitaria ocasionada por el COVID-19. Boletín Oficial del Estado, 67

Ministry of Health of the Czech Republic [MHCR] (2020, May 18). COVID-19 epidemic in the Czech Republic [Onemocněni Aktuálně MZČR]. Ministerstvo zdravotnictvi České republiky. Retrieved from https://koronavirus.mzcr.cz/en/

Muise, A., Boudreau, G. K., \& Rosen, N. O. (2017). Seeking connection versus avoiding disappointment: An experimental manipulation of approach and avoidance sexual goals and the implications for desire and satisfaction. The Journal of Sex Research, 54(3), 296-307. https://doi.org/10.1080/00224499.2016.1152455

Muise, A., Schimmack, U., \& Impett, E. A. (2016). Sexual frequency predicts greater wellbeing, but more is not always better. Social Psychological and Personality Science, 7(4), 295-302. https://doi.org/10.1177/1948550615616462

Pedregosa, F., Varoquaux, G., Gramfort, A., Michel, V., Thirion, B., Grisel, O., ... Duchesnay, E. (2011). Scikit-learn: Machine learning in Python. Journal of Machine Learning Research, 12, 2825-2830. 
Petherick, A., Hale, T., Phillips, T., \& Webster, S. (2020, May $6^{\text {th }}$ ). Variation in government responses to COVID-19. Blavatnik school working paper. Retrieved from https://www.bsg.ox.ac.uk/research/publications/variation-government-responsescovid-19

Pieh, C., O' Rourke, T., Budimir, S., \& Probst, T. (2020). Relationship quality and mental health during COVID-19 lockdown. Plos one, 15(9), e0238906. https://doi.org/10.1371/journal.pone.0238906

Randall, A. K., \& Bodenmann, G. (2009). The role of stress on close relationships and marital satisfaction. Clinical psychology review, 29(2), 105-115. https://doi.org/10.1016/j.cpr.2008.10.004

Randall, A. K., \& Bodenmann, G. (2017). Stress and its associations with relationship satisfaction. Current opinion in psychology, 13, 96-106. https://doi.org/10.1016/j.copsyc.2016.05.010

R Core Team (2017). R: A Language and Environment for Statistical Computing. R Foundation for Statistical Computing, Vienna, Austria. https://www.R-project.org

Richmond, P., \& Roehner, B. M. (2018a). Coupling between death spikes and birth troughs. Part 1: Evidence. Physica A: Statistical Mechanics and its Applications, 506, 97-111. https://doi.org/10.1016/j.physa.2018.04.044

Richmond, P., \& Roehner, B. M. (2018b). Coupling between death spikes and birth troughs. Part 2: Comparative analysis of salient features. Physica A: Statistical Mechanics and its Applications, 506, 88-96. https://doi.org/10.1016/j.physa.2018.04.050

Senchak, M., \& Leonard, K. E. (1992). Attachment styles and marital adjustment among newlywed couples. Journal of Social and Personal Relationships, 9(1), 51-64. https://doi.org/10.1177/0265407592091003

Sibley, C. G., Fischer, R., \& Liu, J. H. (2005). Reliability and validity of the revised experiences in close relationships (ECR-R) self-report measure of adult romantic attachment. Personality and Social Psychology Bulletin, 31(11), 1524-1536. https://doi.org/10.1177/0146167205276865

South, S. C., \& Krueger, R. F. (2013). Marital satisfaction and physical health: Evidence for an orchid effect. Psychological science, 24(3), 373-378. https://doi.org/10.1177/0956797612453116

Thornhill, R., Fincher, C. L., \& Aran, D. (2009). Parasites, democratization, and the liberalization of values across contemporary countries. Biological Reviews, 84(1), 113-131. https://doi.org/10.1111/j.1469-185X.2008.00062.x

Tibshirani, R. (1996). Regression shrinkage and selection via the lasso. Journal of the Royal Statistical Society: Series B (Methodological), 58(1), 267-288. Retrieved from https://www.jstor.org/stable/2346178

Tybur, J. M., Inbar, Y., Güler, E., \& Molho, C. (2015). Is the relationship between pathogen avoidance and ideological conservatism explained by sexual strategies? Evolution and Human Behavior, 36(6), 489-497. https://doi.org/10.1016/j.evolhumbehav.2015.01.006

United Nations [UN] (2020, June). Policy Brief: The Impact of COVID-19 on Food Security and Nutrition. Retrieved from: https://reliefweb.int/sites/reliefweb.int/files/resources/sg_policy_brief_on_covid_impa ct_on_food_security.pdf

World Health Organization [WHO] (2020, July). Coronavirus disease (COVID-19) pandemic. Retrieved from: https://www.who.int/emergencies/diseases/novel-coronavirus-2019

Yehuda, R., Lehrner, A., \& Rosenbaum, T. Y. (2015). PTSD and sexual dysfunction in men and women. The Journal of Sexual Medicine, 12(5), 1107-1119. https://doi.org/10.1111/jsm.12856 
Zakin, G., Solomon, Z., \& Neria, Y. (2003). Hardiness, attachment style, and long term

665 psychological distress among Israeli POWs and combat veterans. Personality and Individual Differences, 34(5), 819-829. https://doi.org/10.1016/S0191-8869(02)000739 